\title{
DIÁLOGOS ENTRE A ARTE CONTEMPORÂNEA E A PUBLICIDADE NA ERA DAS MÍDIAS DIGITAIS
}

\section{Bruna Berger $^{1}$}

\begin{abstract}
Resumo
Este artigo se propõe a refletir sobre os diálogos estabelecidos entre a arte contemporânea e a publicidade na era da cultura digital. Apresenta a publicidade, suas características e práticas enquanto fazer sobretudo criativo e que se instaura, eventualmente, no meio artístico. Ao mesmo tempo, delineia proposições sobre o caráter positivo do desenvolvimento de práticas e produtos culturais e sociais híbridos, que podem desenvolver, mutuamente, a arte contemporânea e a publicidade ao dividirem espaços em comum, como nas mídias digitais.
\end{abstract}

Palavras-chave: Arte contemporânea, publicidade, cultura digital.

\begin{abstract}
This article aims to reflect on the dialogue established between contemporary art and advertising in the age of digital culture. It shows advertising, its characteristics and practices, especially as a creative activity that manifests itself eventually in the artistic world. At the same time, this article outlines propositions about the positive character of the development of hybrid social cultural products and practices, which can develop, mutually, contemporary art and advertising in the same places, such as in digital media.
\end{abstract}

Keywords: Contemporary art, advertising, digital culture.

\section{Introdução}

Enquanto sujeitos inseridos e atuantes nos campos artístico e publicitário, buscando ser conscientes e responsáveis pelas próprias práticas e sabendo-se como produtores e reprodutores de valores e sentidos socioculturais de uma época, refletir o modo como fazemos publicidade e arte torna-se uma necessidade. Identificar e pensar os diferentes modos em que a arte e a publicidade podem interagir e se influenciar entre si torna-se uma atitude pertinente no mundo pós-moderno, que se caracteriza por seus hibridismos socioculturais.

Ao refletir sobre as nossas práticas atuais intermediadas pela tecnologia, podemos visualizar como acontecem as produções atuais e também repensar o modo como os produtos são feitos a partir de então, propondo novos meios de criação. Assim, os diálogos entre a arte contemporânea e a publicidade na era das mídias digitais são pertinentes, uma vez que a tecnologia transformou o conceito de arte aproximando-a cada vez mais dos produtos de massa, bem como da publicidade.

Os diálogos entre a arte contemporânea e a publicidade na era das mídias digitais ainda não possuem contornos definidos, levando a crer que se faz necessária a sua reflexão, a fim de que possamos cada vez mais elaborar produtos de uma forma crítica e consciente das características e transformações que se colocam neste contexto. Assim, este artigo traça um diálogo entre a arte contemporânea e a publicidade, apresentando desde elementos mais

\footnotetext{
${ }^{1}$ Publicitária (UFSM) e especialista em Artes Visuais (SENAC-RS).
} 
tradicionais semelhantes a ambos os domínios, até a constatação de que hoje a arte contemporânea transformou-se a tal ponto que pode ser entendida, do mesmo modo como a publicidade, como um evento de massa.

Deste modo, apresenta-se primeiramente uma leitura da arte contemporânea a partir do conceito da pós-modernidade, buscando definir os agentes que resultaram no fim da arte como a entendíamos até então, para o surgimento da arte contemporânea. A seguir, o item mostra como a publicidade é compreendida, praticada e exigida na contemporaneidade, sobretudo, enquanto um fazer criativo e, por isso, também muitas vezes, artístico. Por fim, no terceiro e último item, já introduzido pelo anterior, o artigo trata dos diálogos entre arte a contemporânea e a publicidade, ao dividirem espaços, linguagens e técnicas, com a proliferação das tecnologias e das mídias digitais.

\section{A arte: uma leitura a partir do conceito da pós-modernidade}

A lógica da cultura do capitalismo, a reconfiguração da questão do tempo e espaço, a tecnologia e a ênfase de viver o presente são algumas das principais características do mundo que vivemos hoje, o mundo pós-moderno. Tal como nos diz o crítico literário marxista e norteamericano Fredric Jameson, "Os últimos anos têm sido marcados por um milenarismo invertido segundo o qual os prognósticos, catastróficos ou redencionistas, a respeito do futuro foram substituídos por decretos sobre o fim disto ou daquilo [...]” (1997, p. 27), o que podemos chamar de pós-modernismo. Dentre os diferentes domínios que tiveram seus fins declarados, está a arte:

\footnotetext{
Reivindicar que a arte chegou a um fim significa dizer que as críticas desse tipo não são mais legítimas. Nenhuma arte é mais historicamente imperativa comparada com qualquer arte. Nenhuma arte é historicamente mais verdadeira do que outra, nem em especial mais falsa. [...] Todos os movimentos eram direcionados por uma percepção da verdade filosófica da arte [...]. Então, cada um dos movimentos via a sua arte em termos de uma narrativa de redescoberta, divulgação ou revelação de uma verdade que fora perdida ou apenas vagamente reconhecida. [...] Uma vez trazida para o nível da autoconsciência, essa verdade revela-se como presente em toda arte relevante: "Nessa medida", como Greenberg observa a certa altura, "a arte permanece imutável" (DANTO, 2006, p. 31-32).
}

Em outras palavras, dizer que a arte chegou ao seu fim não é falar sobre a morte da arte, mas dizer que a arte do modo como nós a entendíamos no mundo moderno já não existe mais, dando lugar a um novo entendimento de arte, em decorrência de seu percurso histórico. A arte passa, então, a ser chamada de arte pós-moderna ou arte contemporânea e assume um caráter diferente do que compreendemos da sua fase moderna, descartando a sua categorização em estilos e inaugurando uma multiplicidade de gêneros que convivem, a priori, harmonicamente em um mesmo universo. Segundo Catherine Millet, crítica de arte francesa, apesar de a arte 
contemporânea ter surgido entre 1960 e 1969, a expressão somente passou a ser amplamente utilizada a partir dos anos 80, ultrapassando os conceitos anteriormente utilizados: vanguarda, arte viva e arte atual. Segundo a autora, foram os conservadores de museus que passaram a questionar o conceito de arte contemporânea:

\begin{abstract}
Os conservadores de museu, segundo parece, foram os primeiros a considerar a noção de arte contemporânea, donde o facto de ter conduzido o inquérito, antes de mais, junto deles. [...] Tomaram, então, consciência da ambiguidade do seu papel: o que significa ser o "conservador" - aquele que assegura a perenidade das coisas - de uma arte em processo e que, sobretudo durante esta segunda metade do século, se terá permitido múltiplas metamorfoses, desvios e subversões? (1997, p. 13).
\end{abstract}

De fato, a arte contemporânea exigiu que se repensasse o valor e a atuação de diferentes instituições que permeiam e constituem este domínio - não só o museu, como também o artista, a galeria, as práticas de história da arte e a disciplina da estética filosófica, como nos fala Danto (2006, p. 21). Com relação aos artistas, os pertencentes à pop art que inauguraram a variedade de estilos que estaria por vir na arte, caracterizando o caráter diversificado e híbrido da arte, assim como também houve, com a pop art, uma valorização da linguagem e suas operações, em detrimento dos métodos convencionais da arte. Neste caso, uma valorização dos produtos industriais, questionando a distinção entre as artes plásticas e a arte comercial.

Aos olhos de Jameson, no entanto, este movimento realizado pela arte seria um sintoma de sua influência pelo mundo pós-moderno, o qual diz respeito à "nova falta de profundidade, que se vê prolongada tanto na 'teoria' contemporânea quanto em toda essa cultura da imagem e do simulacro; um consequente enfraquecimento da historicidade [...]” (1997, p. 32). O que Jameson quer dizer é que todo e qualquer produto cultural não possui profundidade, pois não constitui relações com as coisas do mundo. A profundidade está intimamente ligada à questão do sentido - em todos os assuntos onde há profundidade podemos encontrar sentidos, onde não há sentido está o superficial.

Assim, a arte contemporânea é considerada por Jameson como uma arte vazia e superficial, sem sentido e significado, como podemos perceber a partir de um trecho em que o autor analisa, em comparação à obra Um par de botas de Van Gogh, a obra Diamond dust shoes do artista plástico Andy Warhol: “[...] evidentemente não nos falam com a mesma imediatidade dos sapatos de Van Gogh; de fato, sinto-me tentando a afirmar que não nos dizem absolutamente nada" [1997, p. 34]. Logo, esta superficialidade se estende, é claro, à figura do artista, onde Jameson vê o criador como um sujeito igualmente superficial e fragmentado, que nada tem a dizer, o qual somente reproduz o seu mundo por meio de seu entendimento singular. 
Tal superficialidade e fragmentação viriam da perda de significantes dos sujeitos, no sentido de engajamento social ou político, e da prática constante da cópia de discursos, onde se "vive" somente a experiência dos outros.

Para Millet, entretanto, foi com a pop art de Andy Warhol, Roy Lichtenstein e tantos outros artistas desta linguagem que a arte tornou-se popular, no sentido democrático do termo - a arte tornou-se contemporânea, "falando-nos da nossa vida de todos os dias [...]" (1997, p. 19), de tal modo a transformar o diálogo que a arte possui com o seu público - "Se a arte moderna restabelece a sua relação com o público, a explicação não é apenas sociológica, ela deriva igualmente das novas funções de que a própria arte se atribui e das transformações ocorridas na sua estrutura” (MILLET, 1997, p. 23). Já Danto (2000) considera que a arte encontrou nova forma de expressão e definição com Duchamp e o urinol - para ele seus readymades permitiram que outros artistas passassem a utilizar também objetos não convencionais na arte. Este foi um fator que alterou também o significado do gosto, do prazer estético na arte, para dar lugar a uma era da valorização do sentido na prática artística.

A valorização de uma arte mais conceitual, em seu sentido prático, mostra-nos uma arte onde predomina o empenho na criação do processo na produção de obras de arte. A estética final do objeto artístico já não importa tanto quanto o modo como hoje a arte é produzida, aliando às técnicas tradicionais a tecnologia. Pensando com Lyotard, esta característica da arte contemporânea possivelmente viria com a pós-modernidade, num mundo onde prevalece o “cibernético-informático e informacional”, ou seja, os esforços de informatizar a sociedade e mercantilizar as suas técnicas. Em razão disso, percebemos na arte um movimento de valorização do aspecto técnico e conceitual das obras, em detrimento de sua estética - o que de certa forma parece confrontar com a ideia de superficialidade de Jameson.

Todavia, ao contrário da superficialidade da arte contemporânea pela óptica de Jameson, nota-se igualmente que a arte atual destaca-se como uma produção artística reflexiva e filosófica, da qual vai nos falar Bauman, Danto e Santaella. Especificamente Bauman vê na arte contemporânea uma das principais produtividades pós-modernas: a arte enquanto criadora de imagens e significados, o que pode ser entendido a partir desta passagem: "A arte cria não exatamente as imagens, mas também seus significados, ela 'dá um significado ou um sentido de identidade a algo que não é significativo, que não tem nenhuma identidade"” (BAUMAN, 1998, p. 135). E, a seguir: “a arte e realidade artística funcionam nas mesmas condições, como criadoras de significado e portadoras de significado, num mundo notório por ser 
simultaneamente afortunado e flagelado pela insuficiência e pelo excesso de significados" ( $p$. $135)$.

Neste caso, para Bauman, a arte contemporânea está além de algo que expressa superficialidade, essa arte tem sentido e é uma força crítica e emancipadora quando artista e público consideram, no sentido de elaborar, interpretar e compreender, os infinitos sentidos da vida. Ou seja, possivelmente o significado da arte contemporânea seja desconstruir significados, desconstruindo os significados existentes para, assim, criar outros novos. Poderíamos dizer que Santaella (2009) exprime seu pensamento muito próximo a Bauman, quando diz que a arte é uma das manifestações codificadoras das transformações sociais do mundo pós-moderno. Como podemos visualizar por meio de suas palavras sobre o "vale-tudo" das artes: "[...] longe de indicar ausência de sentido crítico, engajamento ético ou militância política, o 'vale-tudo' estava sinalizando a emergência, brotando do seio do pós-moderno, de um novo tempo pós-utópico na cultura e nas artes” (2009, p. 142).

Não se pode negar o caráter óbvio e superficial que a arte contemporânea pode assumir em sua forma, assim como, de outro modo, encontramos na arte contemporânea significado e sentido. Pensando deste modo, na produção contemporânea, o artista parece ter o papel de imprimir seus sentidos de mundo em sua produção, assim como realiza no seu cotidiano da vida. Não basta ao artista produzir arte contemporânea para se enquadrar no meio artístico, é preciso criar sentidos, significados. A arte contemporânea não possui mais um signo à espera de uma interpretação por conta do espectador. A interpretação deve estar na ação do receptor, ele quem dirá quais são os signos interpretados, de acordo com o seu imaginário e o que a interação com a obra provoca. Ou seja, cabe ao espectador receber a provocação da arte e saber interpretar e compreender os significados que a ela é capaz de transmitir. Tal como nos fala Danto, os artistas tornaram-se pensadores visuais, onde “[...] o sentido das obras está tão fora do alcance do olhar que só temos acesso a elas através de exercícios de interpretação bastante elaborados" (2000, p. 27), a tal ponto que este autor afirma: os artistas são capazes de "fazer filosofia fazendo arte".

\section{A publicidade: fazer criativo e artístico da contemporaneidade}

Vivemos a "apoteose da sedução": terminada a era dos reclames em que os produtos necessitavam somente de uma divulgação de caráter explicativo, a publicidade contemporânea, hoje, exige-se criativa. Devido à concorrência entre as marcas, a criatividade é o principal elemento utilizado na publicidade com a intenção de diferenciar os produtos. Assim, com o 
mérito de atividade criativa, a publicidade pode ser dita como uma comunicação socialmente legítima que atinge a consagração artística, da qual nos falar o sociólogo Lipovetsky: “[...] a publicidade entra no museu, organizam-se exposições retrospectivas de cartazes, distribuem-se prêmios de qualidade, é vendida em cartões postais" (1989, p. 185). Logo, a publicidade tornase sinônimo de fazer criativo, em que "cobiça a arte e o cinema, põe-se a sonhar em abarcar a história" (Idem, ibidem). Deste modo, talvez a primeira das exigências à atividade publicitária seja a criatividade.

O devir da publicidade é em grande parte obra da própria lógica publicitária, do imperativo moda impondo a busca de uma imagem de marca artística. Paralelamente aos estilistas do prêt-à-porter e aos chefes de empresa que se tornaram "criadores", aos cabeleireiros que se designam "estilistas faciais", aos esportistas que se exprimem, aos artesãos que são todos artistas, os publicitários entraram na imensa vaga de valorização social característica das sociedades democráticas: são reconhecidos como "criativos". Assim caminha a era da igualdade: o business ganhou um suplemento de alma, as atividades lucrativas nunca são tanto elas mesmas como no momento em que conseguem elevar-se à dimensão expressiva e artística (LIPOVETSKY, 1989, p. 191).

A publicidade deixa de ser meramente pensada como instrumento que tem como finalidade impulsionar o consumo por meio da informação, para incorporar a isto a valorização plástica do produto, enquanto funcionalidade estética. Lipovetsky (1989) trata a publicidade como sinônimo da alma dos negócios atuais, capaz de ser reconhecida como uma dimensão expressiva e artística. Assim, a publicidade parece ter como "pano de fundo" o capitalismo, ao mesmo tempo em que se pretende ao domínio diverso de sua natureza - da arte - como finalidade visual e conceitual de sua expressão. Mas não só a propriedade visual é conferida à publicidade no momento da sua consagração artística - associa-se a ela também todo o seu status e a empatia do público-espectador. Ainda, nas palavras de Lipovetsky:

A publicidade libertou-se da racionalidade argumentativa, pela qual se obrigava a declinar a composição dos produtos, segundo uma lógica utilitária, e mergulhou num imaginário puro, livre da verossimilhança, aberto à criatividade sem entraves, longe do culto da objetividade das coisas $(2000$, p. 8$)$.

A criatividade é algo inerente ao ser humano. Mesmo em condições de funcionalidade, o sujeito é capaz de exercer a criatividade. No entanto, esta criatividade não pode ser descrita como uma técnica. Ela é, antes, o mecanismo que possibilita a criação de técnicas, "a criação de novas formas de ser" e o "fazer-se de uma forma que não existia" (CASTORIADIS, 1999a, p. 91). A criatividade é, portanto, desprovida de funcionalidade em sua natureza ${ }^{2}$ - ela atua

\footnotetext{
${ }^{2}$ Aqui entendida na sua concepção primordial, de propriedade poiética.
} 
junto ao imaginário e à imaginação - sendo assim, capaz de agir sobre as práticas dos sujeitos, mas jamais substituir a própria prática. Em outras palavras, seria dizer que a prática não é sinônimo de criatividade. Desta forma, pode-se entender a publicidade como uma atividade técnica, que se utiliza da criatividade em suas práticas para determinados fins, de modo que realizou, historicamente, a funcionalização da criatividade.

A criatividade passa a ser definida como o modo em que se pensa e se produz a criação da publicidade. É a propriedade que caracteriza a publicidade como pertencente à esfera artística, enquanto capacidade inventiva e criadora dos sujeitos. A valoração da plasticidade de seus produtos também passa a interferir nessa relação produzida entre publicidade e arte. A publicidade é instantânea, efêmera. Esta instantaneidade da produção publicitária é perfeitamente apropriada ao trabalho exigido pela lógica capitalista, na qual os produtos necessitam constantemente de um novo visual, uma nova forma de comunicar suas potencialidades, havendo uma renovação constante da publicidade. Assim, a publicidade criativa pode ser entendida como a aura artística dos seus produtos. Todavia, a arte é capaz de conferir à publicidade um caráter artístico que nada tem a ver com o sentido de arte tradicional propriamente dita e, sim, possivelmente aproxima-se com o conceito de arte contemporânea.

A arte possui em si uma existência única, sua autenticidade, que pode ser também expressa pelo conceito de aura. Porém esta aura artística encontra-se atrofiada em sua reprodutibilidade técnica, como diz Benjamin: "a técnica da reprodução destaca do domínio da tradição o objeto reproduzido", de forma a alterar o próprio conceito de arte (1987, p. 168). Ou como nos diz Adorno (1970), para que a arte sobrevivesse foi necessária a sua reprodução mecânica, confrontando com as imagens de massa. O que implica dizer que a existência em série da obra de arte substitui qualquer sentido de autenticidade artística.

Foi com este marco da perda da aura da obra de arte com a sua reprodutibilidade técnica, isto é, com o fim da arte e o surgimento da arte pós-moderna ou contemporânea, que a publicidade aproximou-se da arte. O novo conceito de arte e a reprodutibilidade técnica tornou próxima a arte às massas. Assim, a publicidade apropria-se de características pertinentes à arte, como o uso da criatividade, e ainda se utiliza das suas próprias imagens incorporando em seus produtos o status da arte. Já a arte contemporânea utiliza-se dos objetos de consumo e suas características, tal qual a própria publicidade, para a produção de suas obras. A introdução de novas técnicas é um fator que modificou a experiência e o modo de perceber a arte, espaço onde só há lugar, hoje, para a criação e reprodução de novas percepções, distintas daquelas já vivenciadas durante o período da arte moderna. Santaella vai ao encontro desse pensamento: 
Quantas tintas foram gastas na discussão se a fotografia era arte ou não! E o cinema? Por que ultrapassou a fronteira de mero entretenimento das massas para ascender ao panteão de sétima arte? Essas dificuldades, entretanto, pareciam brincadeiras de criança quando comparadas às complicações que os meios de comunicação e difusão eletrônicos de massa (rádio e TV) iriam trazer. Depois deles, tudo na cultura foi virando mistura (2003, p. 56).

Um dos domínios que parece misturar-se com a arte no espaço das mídias digitais é a publicidade. Enquanto reprodução do artístico ela apropriou-se de conceitos tradicionais, como a criatividade, tal qual a reprodução técnica do som também o fez. Segundo nos fala Benjamin, esta "atingiu tal padrão de qualidade que ela não somente podia transformar em seus objetos a totalidade das obras de arte tradicionais, submetendo-as a transformações profundas" como também conquistou "para si um lugar próprio entre os procedimentos artísticos" (1987, p. 167). Nestes moldes, a atividade publicitária parece poder ser representada como uma forma de arte ou arte popular. Para John Berger, crítico de arte e escritor inglês, a publicidade sempre compartilhou de signos em comum com a arte, falando com a mesma voz sobre as mesmas coisas. Já David Harvey vai mais longe ao considerar a publicidade "a arte oficial do capitalismo", que "traz para a arte estratégias publicitárias e introduz a arte nessas mesmas estratégias [...]" (1999, p. 65).

Em suma, o lugar próprio da publicidade parece ser o lugar da criatividade funcional assim, ao mesmo tempo em que recorre a uma estética artística, a publicidade cumpre sua função original, do pragmatismo dos negócios, da funcionalidade e, instaurando-se, eventualmente, no meio artístico.

\section{Diálogos em devir entre a arte contemporânea e a publicidade na era das mídias digitais}

Não é de hoje que discutimos sobre a confluência entre arte e comunicação, contudo, cada vez mais vemos a arte se manifestar nos meios próprios da comunicação e também na publicidade que sustenta, financeiramente, em sua maior parte, esses meios. Os diálogos entre arte e publicidade não são novos ou originais, no entanto, justamente pela configuração em que vivemos da pós-modernidade, também não chegaram a ponto de esgotar novas reflexões e propor novas leituras acerca das características compartilhadas por estes dois domínios. Vários são os pontos em comum que podemos visualizar entre arte e publicidade e são vários também os espaços de manifestações em que elas convergem.

Ambas glorificam o novo, buscam o original, trabalham com formas e conceitos inéditos para despertar o interesse e o diálogo com o público-espectador, além de, é claro, emocionar. 
A publicidade, em geral, deseja que o espectador entenda a sua mensagem de um modo rápido, tornando-a banal e efêmera. Parece dizer ao consumidor: não pense, compre já. Ao mesmo tempo, visualizamos também manifestações da publicidade que nos fazem refletir e que constroem um diálogo entre o consumidor e a marca, garantindo a sua fidelização, como por exemplo, no trabalho de branding ${ }^{3}$. Já a arte teria inerente a ela um valor filosófico, que nos impele a refletir. A arte parece incorporar um sentido de diálogo em aberto. No entanto, a arte contemporânea parece caminhar também para o mesmo aspecto de instantaneidade, quando pensamos nela enquanto experiência visual que só se pode vivenciar em determinado tempo e espaço, ficando somente seu registro para a posteridade, como é o caso das instalações e performances.

Tanto a arte contemporânea quanto a publicidade poderiam ser ditas como elitistas, uma vez que selecionam o público com que interagem ou desejam interagir. Exigem certo conhecimento cultural para que possam ser assimiladas. Pensando na utilização de ambientes virtuais e da tecnologia, destinam-se não só a quem tem acesso a estes dispositivos, como também a quem detém o conhecimento de interação com tais meios. Ainda que falemos em comunicação de massas, característica da publicidade, o seu objetivo final, que é vender o produto ou serviço, só será alcançado por aqueles que detêm meios financeiros para realizar a compra, excluindo quem não possui tal capital. Já a arte está, ainda em sua maioria, ainda que caminhe em direção à arte pública, restrita aos museus e exposições, aos quais a baixa cultura não possui acesso ou não possui gosto e conhecimento para apreciação e frequentação desses espaços. Ao mesmo tempo, a arte é de um valor comercial relativamente alto, selecionando também o seu público consumidor.

$\mathrm{Na}$ arte é possível ser ao mesmo tempo artista e contemplador, e destas, há de se pensar suas relações, como já dizia Adorno (1970). Assim, quanto à relação da arte com os sujeitos, este autor separa-o em duas categorias: o sujeito sentimental e o sujeito reflexivo. Adorno (idem) considera que o sujeito sentimental frente às obras de arte vê as obras com intenções. Esse sujeito deseja compreender-se por meio da ação de contemplar determinada obra de arte, ao invés de deixar que a arte comunique-se com ele próprio. Agindo desse modo, tornam as obras de arte silenciosas quanto aos seus conteúdos - se buscamos apenas características com as quais possamos nos identificar e encontrar a si mesmos, não deixamos a obra falar o que tem a nos dizer. Esse sujeito não questiona ou reflete sobre a obra de arte, mas realiza somente

\footnotetext{
${ }^{3}$ Branding designa o trabalho de gestão de marca, é utilizado nas agências de publicidade, design e marketing.
} 
inclinações e projeções do próprio eu sobre a obra de arte. A obra somente comunica-se com o sujeito reflexivo, aquele que é capaz de captar o seu procedimento e a sua linguagem.

É exatamente do sujeito sentimental que a indústria cultural, por sua vez, tira seu proveito, explorando tal comportamento. Trazendo esta leitura de Adorno com a arte para a publicidade, poderíamos dizer que na atividade publicitária se é preciso pensar ao mesmo tempo como publicitário e sujeito consumidor. A publicidade parece fazer o movimento contrário do caráter crítico social da obra de arte. Segundo os autores Vestergaaard e Shrøder, os anúncios "funcionam ao nível do devaneio" (2004, p. 179), comunicando-se com os seus públicos de forma a evidenciar, por exemplo, os excessos de beleza, juventude e felicidade de forma a construir "um universo imaginário em que o leitor consegue materializar os desejos insatisfeitos da sua vida diária" (ibidem, idem). Mas ao afirmar a beleza, a juventude e a felicidade, afirma também que existem as suas antagônicas: a feiura, a velhice e a infelicidade.

Adorno (1970) nos fala também sobre a sublimação estética que seria o movimento em que o sujeito, ao contemplar a obra de arte, reduz-se a ela, isto é, projeta as suas emoções próprias e subjetivas à obra. Assim, o indivíduo torna-se sujeito pela sua alienação, também chamado pelo autor de "veículo da psicologia do espectador". Trazendo esta leitura para a publicidade, poderíamos dizer que ela também faz esse movimento com a sua estética - deseja que o espectador se imagine dentro da propaganda, de forma a incorporar algum de seus personagens e também todos os valores e símbolos incorporados à mensagem publicitária. Do mesmo modo como trata Vestergaaard e Shrøder:

\footnotetext{
Convidando-nos a entrar no seu paraíso imaginário, a propaganda se torna assim um espelho mágico, no qual uma interpretação mais sutil nos permite discernir os contornos do generalizado descontentamento popular com a vida cotidiana e com as oportunidades que nos proporciona a sociedade em que vivemos. Portanto, a publicidade se fundamenta no desejo subconsciente de um mundo melhor (2004, p. 183).
}

E dentre os pontos dissonantes entre arte e publicidade estaria o seu objeto motivador. Enquanto a arte seria o resultado de uma manifestação espontânea, expressão pessoal e íntima do artista, fenômeno natural do humano, a publicidade seria uma atividade inscrita no capitalismo, com fins meramente mercantis. $\mathrm{O}$ artista se expressa e produz as suas obras para dar sentido à sua vida, logo tais obras comunicam a sua visão de mundo. Já o publicitário cumpre o papel social e cultural de propagar os produtos e serviços do mercado e seus valores de marca, utilizando-se de artifícios criativos, tais como o estético e o poético. Logo, a publicidade é entendida como um fenômeno decorrente da lógica capitalista e não seria uma atividade vinculada à natureza do humano. 
Porém há uma discussão quanto à finalidade mercadológica também das obras de arte, já que hoje seria impossível considerar produtos ou objetos fora dos recônditos do capitalismo. Enquanto objetos que possuem valor mercadológico e estampam catálogos de venda e de museus, além das curadorias, críticas e encomendas realizadas, a arte é também mercadoria. Além disso, a arte contemporânea - e aqui poderia ser destacada a arte especialmente interativa - apoia-se em uma construção de arte que seja capaz de atrair e persuadir determinado público para que com a obra interaja. Cada vez mais tais artistas estudam e impulsionam-se para atrair olhares a fim de que as pessoas vejam, interpretem, compreendam e interajam com as obras. É por meio de suas obras, também, que os artistas se autodivulgam na mídia a fim de obter reconhecimento e sucesso da crítica e da sociedade - assim, não estaria sendo a obra de arte a própria publicidade do artista?

Sobre a diferença entre objetos artísticos e não artísticos, Santaella nos diz: “O que irá diferenciar estas criações artísticas das não artísticas será a intencionalidade do artista ao criar algo que não sofra os constrangimentos de quaisquer outros propósitos a não ser os da própria criação" (2000, p. 57). Pensamento semelhante tem Millet ao dizer que: “[...] não somos simplesmente convidados a contemplar as obras de certa forma inacabadas, temos igualmente de decidir se o estatuto de certos objectos será o de uma obra de arte” (1997, p. 43). O que quer dizer que os objetos só serão entendidos como propostas de obras de arte sob a aceitação do nosso olhar. Priscila Arantes, crítica, teórica e pesquisadora em arte, relaciona a teoria de Benjamin da reprodutibilidade técnica com os dias de hoje:

O momento da obra de arte na atualidade, no entanto, já não diz mais respeito somente à era da reprodutibilidade técnica, mas à era digital, a esse momento histórico permeado pela revolução da informática e por sua confluência com os meios de comunicação (2005, p. 18).

Assim, talvez o que mais nos faz pensar hoje na aproximação entre arte contemporânea e publicidade seja a técnica compartilhada por ambos os domínios, pensando do ponto de vista da técnica enquanto modus operandi, o modo como os produtos da arte contemporânea e da publicidade são feitos. Do grego tekhne, a palavra técnica tem sua origem referente à arte e ao trabalho do artesão, referindo-se a uma habilidade específica. Trazendo este conceito para a contemporaneidade, a técnica é intermediada ou produzida a partir das novas tecnologias e das redes de comunicação em escala mundial. Assim, as mídias e as tecnologias vão sendo incorporadas pela atividade artística, bem como a publicidade adapta sua linguagem para 
abarcar os públicos cibernéticos e se insere nos espaços virtuais, ampliando a convergência entre esses dois domínios. Segundo Arlindo Machado,

\begin{abstract}
As técnicas, os artifícios, os dispositivos de que se utiliza o artista para conceber, construir e exibir seus trabalhos não são apenas ferramentas inertes, nem mediações inocentes, indiferentes aos resultados, que se poderiam substituir por quaisquer outras. Eles estão carregados de conceitos, eles têm uma história e derivam de condições produtivas bastante específicas. A arte mídia, como qualquer arte fortemente determinada pela mediação técnica, coloca o artista diante do desafio permanente de, ao mesmo tempo em que se abre às formas de produzir do presente, contrapor-se também ao determinismo tecnológico, recusar o projeto industrial já embutido nas máquinas e aparelhos, evitando assim que sua obra resulte simplesmente num endosso dos objetivos de produtividade da sociedade tecnológica (2007, p. 16-17).
\end{abstract}

Portanto, ao mesmo tempo em que a publicidade ocupa espaços nas mídias digitais, a arte contemporânea apropria-se também destes meios para produzir de forma inovadora em benefício das ideias estéticas. A artemídia, expressão de origem inglesa media art, designa as "formas de expressão artística que se apropriam de recursos tecnológicos das mídias e da indústria do entretenimento em geral, ou intervêm em seus canais de difusão, para propor alternativas qualitativas", segundo Machado (2007, p. 7). Ao mesmo tempo, para este autor, a artemídia representa a "metalinguagem da sociedade midiática, na medida em que possibilita praticar, no interior da própria mídia e de seus derivados institucionais [...] alternativas críticas aos modelos atuais de normatização e controle da sociedade" (2002, p. 25). Para Arantes, a expressão ainda sem consenso terminológico "arte em mídias digitais" seria a mais adequada para designar "essa parcela da artemídia que faz uso das mídias digitais para o desenvolvimento de propostas estéticas" (2005, p. 24).

Como podemos ver, enquanto a publicidade se apropria de modo criativo e estético das mídias digitais para vender suas ideias e seus produtos, a arte contemporânea se utiliza dessas mídias como suporte para suas experiências a fim de criar suas obras. Logo, parece que a arte contemporânea e a publicidade passam a frequentar hoje um mesmo espaço e a dialogar cada vez mais entre si, explorando, mutuamente, tais mídias e também, diferentes técnicas. Como nos diz Arantes, "[...] as produções artísticas em mídias digitais são mediadas por uma interface técnica, por um elemento intermediário que permite a troca de informações entre os homens e as máquinas" (2005, p. 65). Assim acontece igualmente entre consumidor e marcas trabalhadas pela propaganda nas mídias digitais, sua interação com as mídias digitais pressupõe que aconteça uma experiência de relacionamento social e muitas vezes afetiva entre sujeito e marca, assim como com os seus produtos. 
Utilizando-se de estratégias semelhantes para inserir-se nas mídias digitais, a arte contemporânea e a publicidade passam a dividir um mesmo espaço, ainda que tenham intencionalidades diferentes. Neste ponto, poderíamos citar Machado, ao dizer que "não há também nenhuma razão para esses produtos qualitativos da comunicação de massa não serem considerados verdadeiras obras criativas do nosso tempo, sejam elas vistas como arte ou não" (2007, p. 25). Isto porque, segundo o mesmo autor, os limites entre os meios de comunicação e os fatos da cultura humana, tal como a arte contemporânea, são cada vez menos visíveis, onde os "conceitos que os definem podem ser transportados de uns para outros e as práticas e tecnologias podem ser compartilhadas" (idem, p. 59). Para ilustrar sua ideia, o autor cita a fotografia, o cinema, a televisão e o vídeo, como mídias bastante semelhantes em muitos aspectos que foram, contudo, até então "pensados e praticados de forma independente, por gente diferente, e esses grupos quase nunca se comunicavam ou trocavam experiências" (idem, p. 63). O que seria um valor negativo para a sociedade, a seu ver, pois processos isolados "podem levar à intolerância e à guerra entre culturas, enquanto os processos de hibridização podem favorecer uma convivência mais pacífica entre as diferenças" (idem, p. 64).

Assim, poderíamos pensar a publicidade - definindo a sua natureza, enquanto um fazer criativo e com fins mercadológicos e que possui suas limitações - como um produto que certamente pode compartilhar com a arte contemporânea suas experiências em torno das mídias digitais. Isto porque a publicidade compartilha com a arte, como já foi dito, o fazer estético e poético. Neste sentido, Machado reflete e legitima este pensamento: se pensássemos o cinema enquanto "escrita do movimento" e então selecionássemos todas as formas de expressão baseadas nesse conceito, televisão e vídeo, ambos seriam considerados cinema. Esse novo caráter da televisão e do vídeo renovariam seus significados, garantindo sua hegemonia perante outras formas de cultura. Millet parece pensar semelhante ao rememorar um pensamento do crítico de arte Lawrence Alloway: "O novo papel atribuído às belas-artes é o de representar uma das formas possíveis de comunicação no seio de um sistema em expansão, que inclui igualmente as artes de massa" (ALLOWAY apud MILLET, 1997, p. 26).

Por fim, Machado considera que a hibridização e a convergência dos meios são “processos de intersecção, de transações e de diálogo, implicam movimentos de trânsito e provisoriedade, implicam também as tensões dos elementos híbridos convergidos, partes que se desgarram e não chegam a fundir-se completamente" (2007, p. 78). Ou seja, na verdade o que se é produzido com a convergência de diferentes domínios, com a múltipla expressão, como fala o autor, são novos produtos com novas linguagens, resultado de uma ressignificação de 
valores e conceitos que deverão, por sua vez, ser assimilados como produtos híbridos. Assim como a publicidade, a arte contemporânea agora também passa a ser um produto das comunicações de massa: "Ao ser excluída dos seus guetos tradicionais, que a legitimavam e a instituíam como tal, a arte passa a enfrentar agora o desafio da sua dissolução e da sua reinvenção como evento de massa" (2002, p. 31).

\section{Conclusão}

Refletir sobre as novas possibilidades e experiências realizadas nos campos da arte contemporânea e da publicidade no pós-moderno, pensando na confluência e no maior diálogo estabelecido entre ambos os domínios por meio das mídias digitais, é também um diálogo contínuo e inovador. Já que as mídias digitais são ainda relativamente recentes e estão em constantes transformações, historicamente seus efeitos sobre a sociedade ainda estão longe de serem concluídos. Ainda assim, é preciso refletir sobre a relação entre os produtos culturais tecnológicos e a sociedade para, a partir desta reflexão, repensarmos nossas práticas sociais atuais. Com isto, estaremos também demonstrando o cuidado que se deve ter na criação de produtos culturais, estabelecendo uma linguagem crítica e responsável, seja na arte ou na publicidade, ou como quer, na sua convergência.

(Artigo recebido em 04/08/2013, aprovado em 18/08/2013)

\section{REFERÊNCIAS}

ADORNO, T. W. Teoria Estética. Trad. Artur Morao. Lisboa: Edições 70, 1970.

ARANTES, P. @ rte e mídia: perspectivas da estética digital. São Paulo: Editora Senac, 2005.

BAUMAN, Z. O Mal-Estar da Pós-Modernidade. Rio de Janeiro: Jorge Zahar, 1998.

BENJAMIN, W. Magia e técnica, arte e política: Ensaios sobre literatura e história da cultura. Trad. Sergio Paulo Rouanet. 3.ed. São Paulo: Brasiliense, 1987.

CASTORIADIS, C. A instituição imaginária da sociedade. Trad. Guy Raynaud. São Paulo: Paz e Terra, 1982.

DANTO, A. C. Após o fim da arte: a arte contemporânea e os limites da história. Trad. Saulo Krieger. São Paulo: Odysseus Editora, 2006.

Baixos. 2000.

. Marcel Duchamp e o fim do gosto: uma defesa da arte contemporânea. Países

HARVEY, D. Condição pós-moderna: uma pesquisa sobre as origens da mudança cultural. Trad. Adail Ubirajara Sobral e Maria Stela Gonçalves. 8.ed. São Paulo: Edições Loyola, 1999.

JAMESON, F. Pós-modernismo: a lógica cultural do capitalismo tardio. São Paulo: Editora Ática, 1997. 
LIPOVETSKY, G. O império do efêmero: a moda e seu destino nas sociedades modernas. Tradução: Maria Lucia Machado. São Paulo: Companhia das Letras, 1989.

LYOTARD, J-F. O pós-moderno. Rio de Janeiro: José Olympio Editora, 1988. E 3. ed. MACHADO, A. Arte e mídia. Rio de Janeiro: Zahar, 2007.

MILLET, C. L'Art Contemporain. Tradução: Joana Chaves. Lisboa: Instituto Piaget, 1997. $147 \mathrm{p}$.

SANTAELLA, L. O pluralismo pós-utópico da arte. ARS (São Paulo) [online]. 2009, vol.7, n.14, p. 130-151.

Paulo: Paulus, 2003.

Culturas e artes do pós-humano: da cultura das mídias à cibercultura. São

VESTERGAARD, T; SCHRØDER, K. C. A linguagem da propaganda. Trad. João Alves dos Santos. São Paulo: Martins Fontes, 2004. 